\title{
Corporate-Feed Multilayer Bow-Tie Antenna Array Design Using a Simple Transmission Line Model
}

\author{
S. Didouh, M. Abri, and F. T. Bendimerad \\ Telecommunications Laboratory, Faculty of Technology, Abou-Bekr Belkaid University, 13000 Tlemcen, Algeria \\ Correspondence should be addressed to M. Abri, abrim2002@yahoo.fr
}

Received 16 April 2012; Revised 16 October 2012; Accepted 9 November 2012

Academic Editor: S. Taib

Copyright () 2012 S. Didouh et al. This is an open access article distributed under the Creative Commons Attribution License, which permits unrestricted use, distribution, and reproduction in any medium, provided the original work is properly cited.

\begin{abstract}
A transmission line model is used to design corporate-fed multilayered bow-tie antennas arrays; the simulated antennas arrays are designed to resonate at the frequencies $2.4 \mathrm{GHz}, 5 \mathrm{GHz}$, and $8 \mathrm{GHz}$ corresponding to RFID, WIFI, and radars applications. The contribution of this paper consists of modeling multilayer bow-tie antenna array fed through an aperture using transmission line model. The transmission line model is simple and precise and allows taking into account the whole geometrical, electrical, and technological characteristics of the antennas arrays. The proposed transmission line model showed its interest in the design of different multilayered bow-tie antennas and predicted the correct resonance frequency for different applications in telecommunications. To validate the proposed transmission line model, the simulation results obtained are compared with those obtained by the method of moments. The results of simulations are presented and discussed. Using this transmission line approach, the resonant frequency, input impedance, and return loss can be determined simultaneously. The paper reports several simulation results that confirm the validity of the developed model. The obtained results are then presented and discussed.
\end{abstract}

\section{Introduction}

Microstrip antenna arrays are exploited in a vast number of engineering applications due to their ease of manufacturing, low cost, low profile, and light weight $[1,2]$.

Antenna arrays are used to scan the beam of an antenna system, increase the directivity, and perform various other functions which would be difficult with any single element. In the microstrip array, elements can be fed by a single line or by multiple lines in a feed network arrangement. Based on their feeding method [3-5] the array is classified in seriesfeed network or corporate-feed network.

Corporate-feed network is general and versatile because it offers the designer more freedom in controlling the feed of each element (amplitude and phase). Although it leads to performance degradation due to radiation, its constructional simplicity and low cost are still considered. This method has more control of the feed of each element and is ideal for scanning phased arrays, multiband arrays. Thus it provides better directivity as well as radiation efficiency and reduces the beam fluctuations over a band of frequencies compared to the series-feed array. The corporate-feed network is used to provide power splits of $2 n$ (i.e., $n=2,4,8,16$, etc.). This is accomplished by using either tapered lines or using quarter wavelength impedance transformers.

In this paper, a transmission line model is used to design corporate-feed multilayer antennas arrays to resonate at the frequencies of $2.4 \mathrm{GHz}, 5 \mathrm{GHz}$, and $8 \mathrm{GHz}$ corresponding to RFID, WIFI, and radars applications, and the patches chosen as radiating elements for these arrays are in the bow-tie shape. The obtained simulation results are compared with those obtained by the moment's method (MoM).

\section{Transmission Line Model Analysis}

The preferred models for the analysis of microstrip patch antennas are the transmission line model, cavity model, and full wave model (which include primarily integral equations/Moment Method). The transmission line model is the simplest of all and it gives good physical insight, but it is less accurate. 


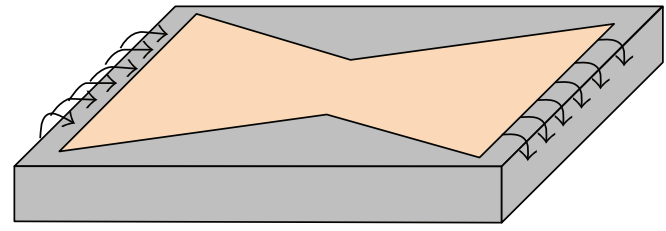

(a)

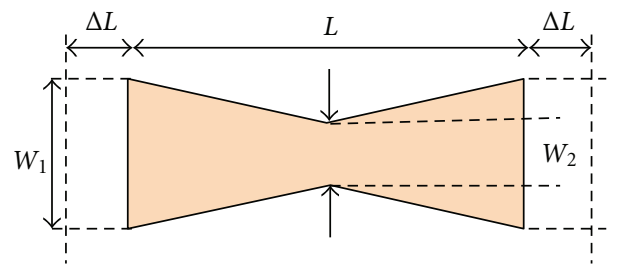

(b)

FIgURE 1: Bow-tie antenna and its effective length.

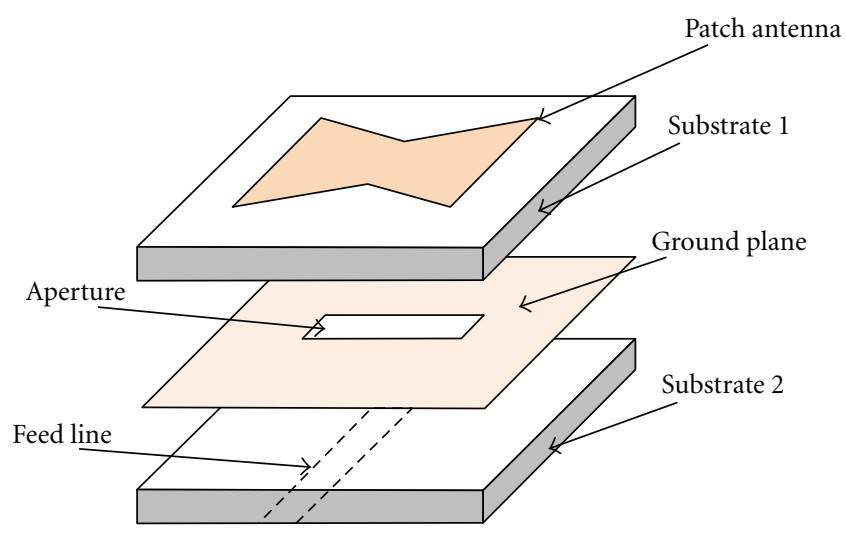

FIGURE 2: Configuration of bow-tie antenna fed by aperture coupled.

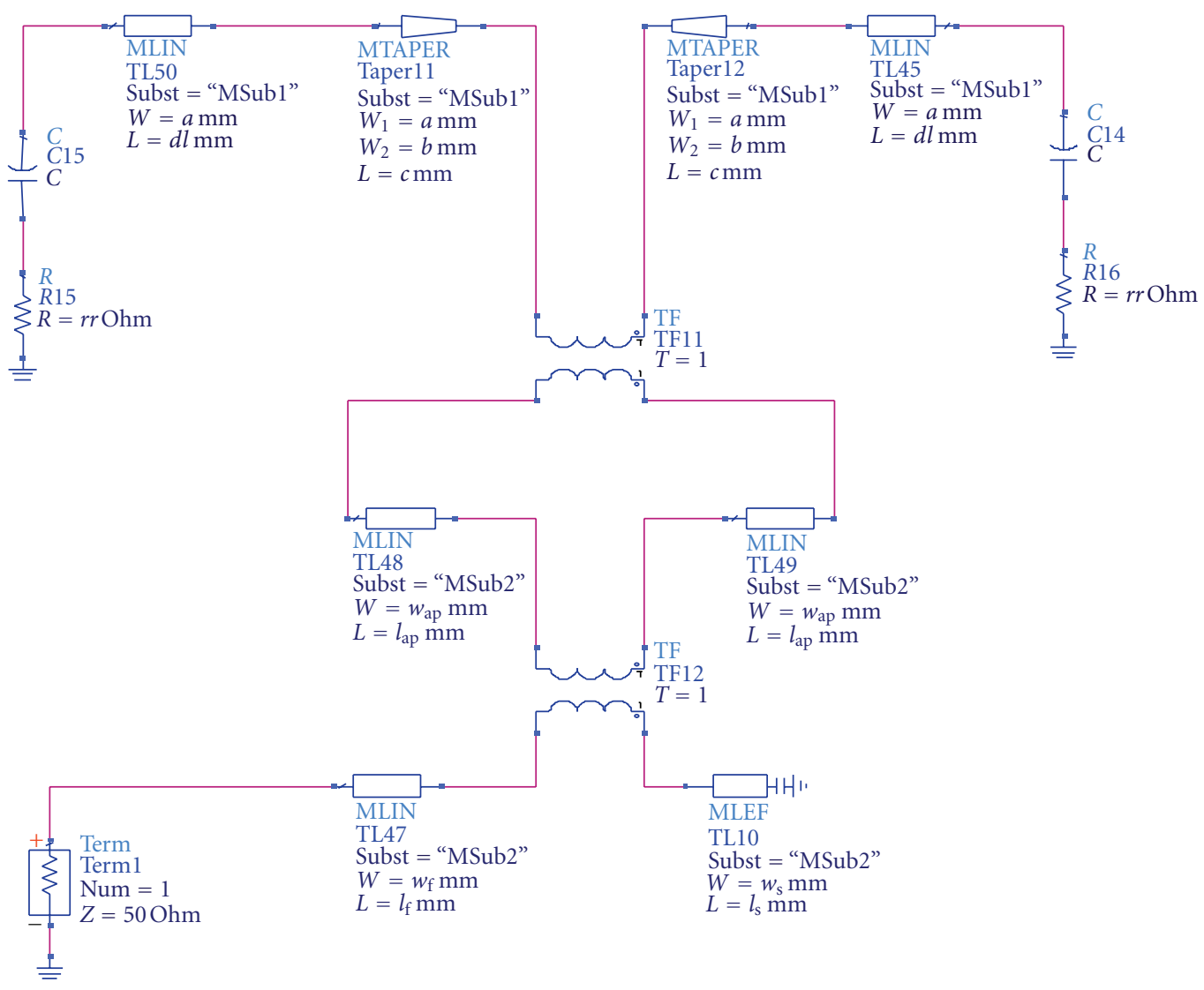

FIGURE 3: Equivalent circuit of the proposed antenna. 


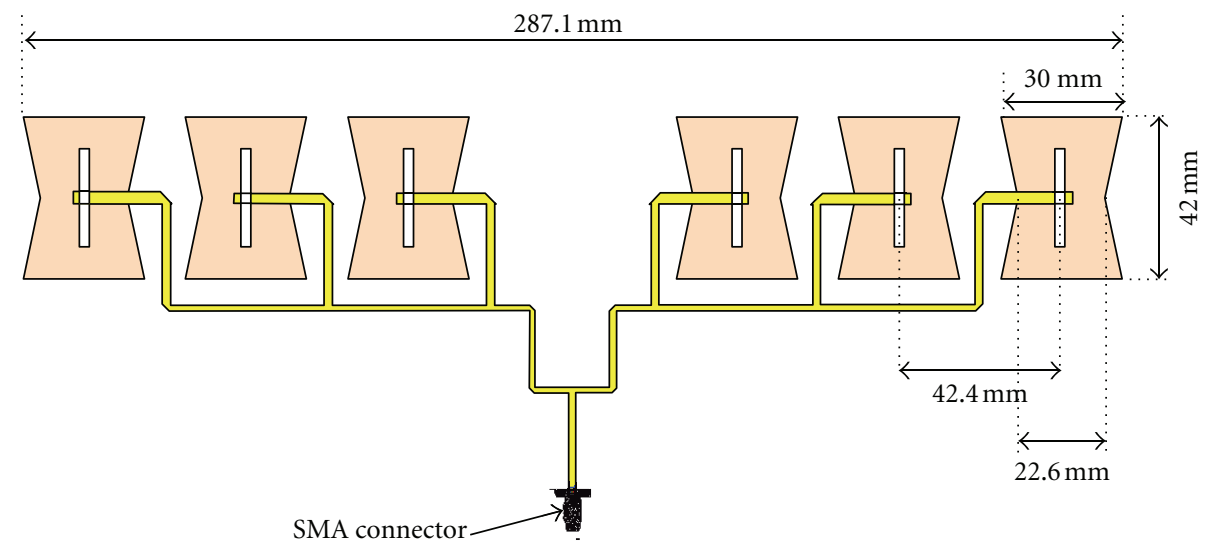

FIGURE 4: Mask of the multilayered bow-tie antenna array operating at the frequency $2.4 \mathrm{GHz}$.

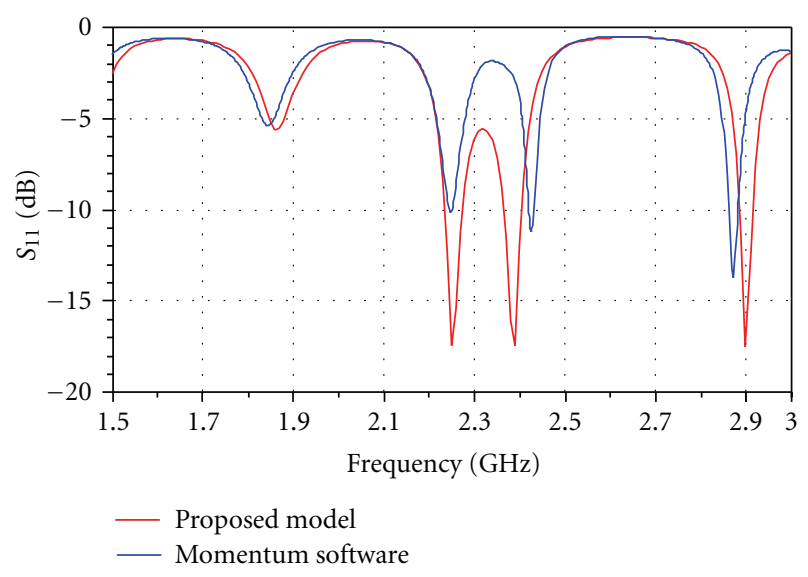

FIgURE 5: Simulated input antenna array return loss.

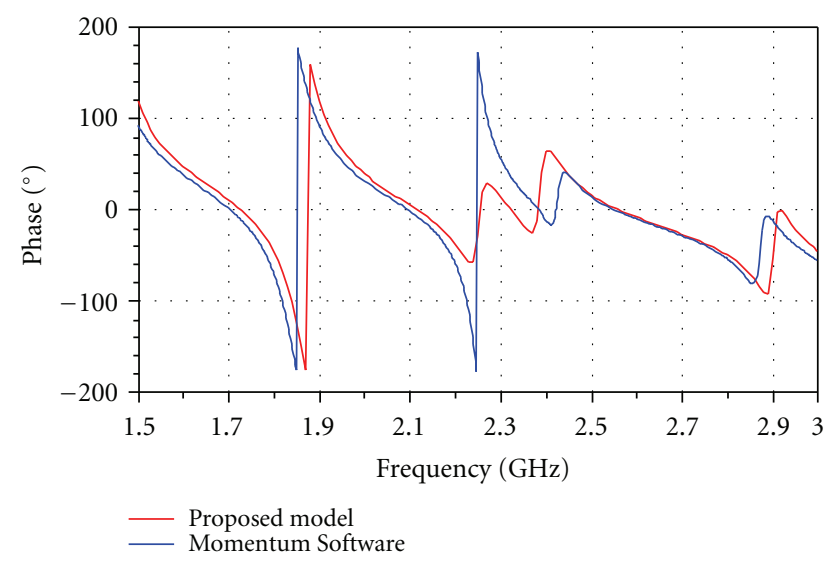

FIgURE 6: Reflected phase at the antenna array input.

In this study, six bow-tie microstrip radiating elements are used to design the corporate-fed array antenna. A bowtie microstrip radiating patch which is shown in Figure 1 can be considered as an open-ended transmission line of length $L$ and width $W$.

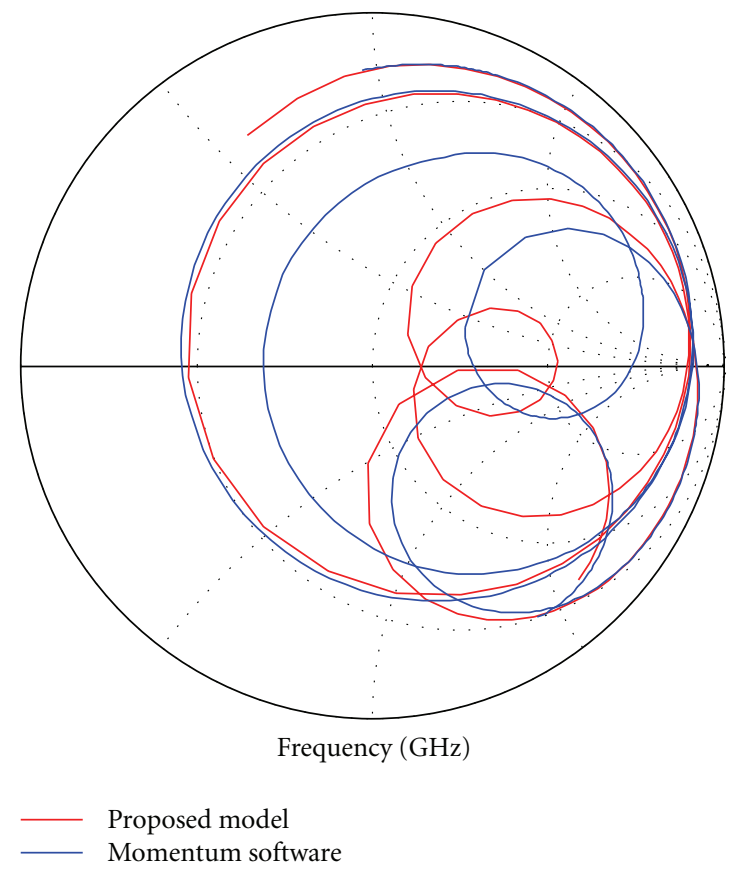

FIGURE 7: Smith's chart of the input impedance return losses.

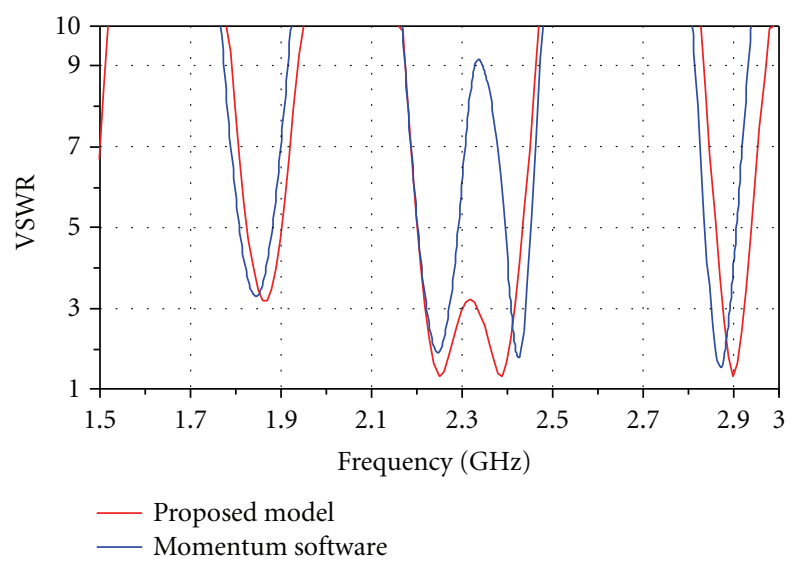

FIGURE 8: Bow-tie antennas array VSWR. 


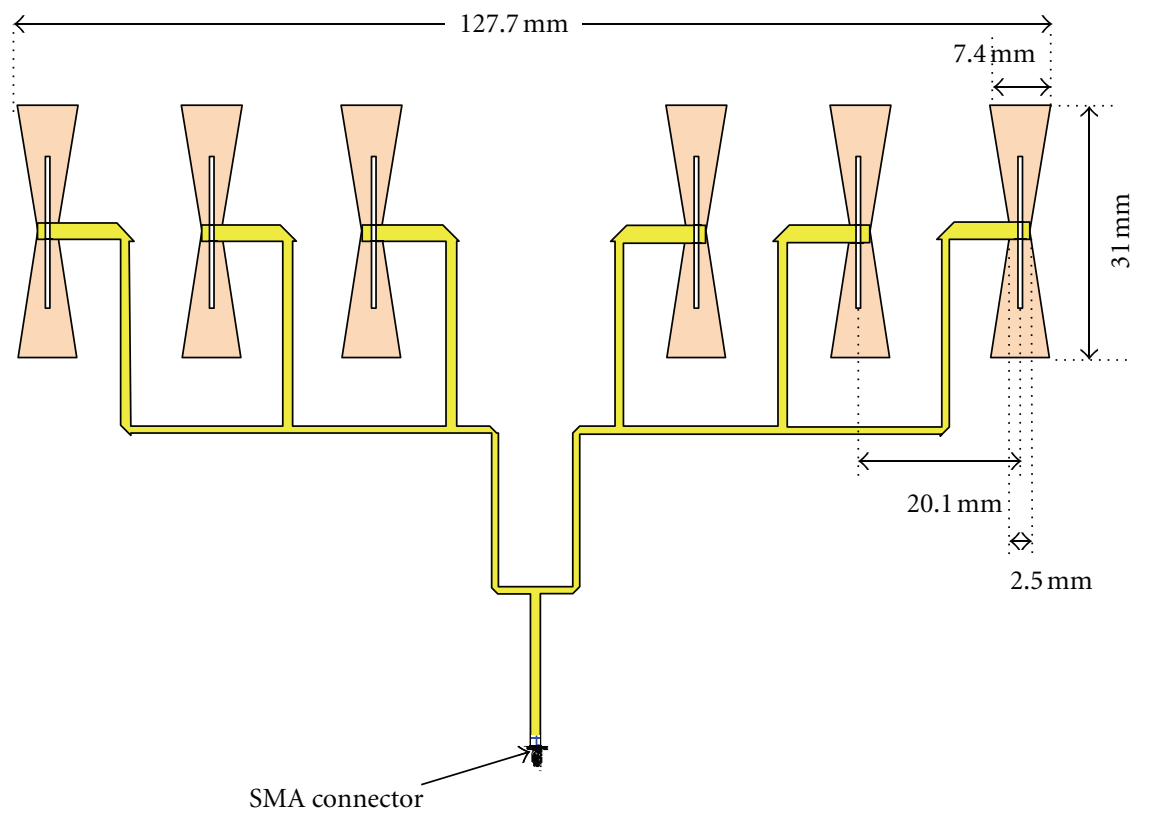

FIGURE 9: Mask of the multilayered bow-tie antenna array operating at the frequency $5 \mathrm{GHz}$.

\section{Microstrip Corporated-Feed Array Antenna}

The printed array to be considered is one using aperturecoupled bow-tie microstrip patches. The aperture-coupled patch element $[4,6]$ consists of two substrates, with a ground plane in between. As shown in the geometry for a single aperture-coupled patch in Figure 2, a microstrip feed line is printed on the bottom (feed) substrate, while the patch element is printed on the top (antenna) substrate. Coupling between the feed line and the radiating element is through a small slot in the ground plane below the patch.

The proposed transmission line equivalent circuit for an aperture coupled bow-tie antennas fed via microstrip line is shown in Figure 3.

In this equivalent circuit, two ideal transformers are assumed between the slot ground plane and both sides of the line. The energy is transferred and stored in these two transformers in terms of load susceptance. In fact, all the energy passes the slot aperture and delivers to the patch for radiating. The ratios of these two transformers can be determined using [4]:

$$
n_{1}=\frac{L_{\mathrm{ap}}}{L}
$$

where $L_{\text {ap }}$ is the length of the slot.

While the second transformation ratio $n_{2}$ can be approximated by the expression:

$$
n_{2}=\frac{L_{\mathrm{ap}}}{\sqrt{W \cdot h}}
$$

where $h$ is the thickness of the substrate, the capacitance $C$ is calculated using the following equation as in [7]:

$$
\begin{gathered}
C(\varepsilon)=\frac{\varepsilon_{0} \varepsilon_{r} A}{h \gamma_{n} \gamma_{m}}+\frac{1}{2 \gamma_{n}}\left(\frac{\varepsilon_{\text {reff }}\left(\varepsilon_{r}, h, W\right)}{c_{0} Z\left(\varepsilon_{r}=1, h, W\right)}\right)-\frac{\varepsilon_{0} \varepsilon_{r} A}{h}, \\
\gamma_{j}= \begin{cases}1, & j=0 \\
2, & j \neq 0 .\end{cases}
\end{gathered}
$$

\section{Results and Discussions}

The validity of the suggested model is highlighted by comparing the results of the return loss, the input phase, input antenna VSWR, and input impedance locus to those obtained by the moment's method of the Momentum Software. The simulated antennas arrays are designed to resonate, respectively, at the frequencies $2.4 \mathrm{GHz}$ and $8 \mathrm{GHz}$.

4.1. Bow-Tie Antenna Array Operating at the Resonant Frequency $2.4 \mathrm{GHz}$. The configuration of the proposed array is shown in Figure 4, which consists of 6 identical bowtie patch elements in parallel or corporate feed to cover 2.4 GHz operating frequency. The corporate feed has a single input port and multiple feed lines in parallel constituting the output ports. Each of these feed lines terminates at an individual radiating element and therefore transfers all its energy into the element.

The antenna array is to be designed on substrate which has a relative permittivity $\varepsilon_{r}$ of 2.54 , a dielectric thickness $h$ of $1.6 \mathrm{~mm}$, and a loss tangent of about 0,019 and $0.05 \mathrm{~mm}$ conductor thickness. A rectangular slot with $L_{\mathrm{ap}}=26 \mathrm{~mm}$ and width $W_{\text {ap }}=2.6 \mathrm{~mm}$ is used for coupling the patch to a microstrip line of length $L_{f}=20 \mathrm{~mm}$, etched on substrate which has a relative permittivity $\varepsilon_{r}$ of 2.54 , a dielectric 


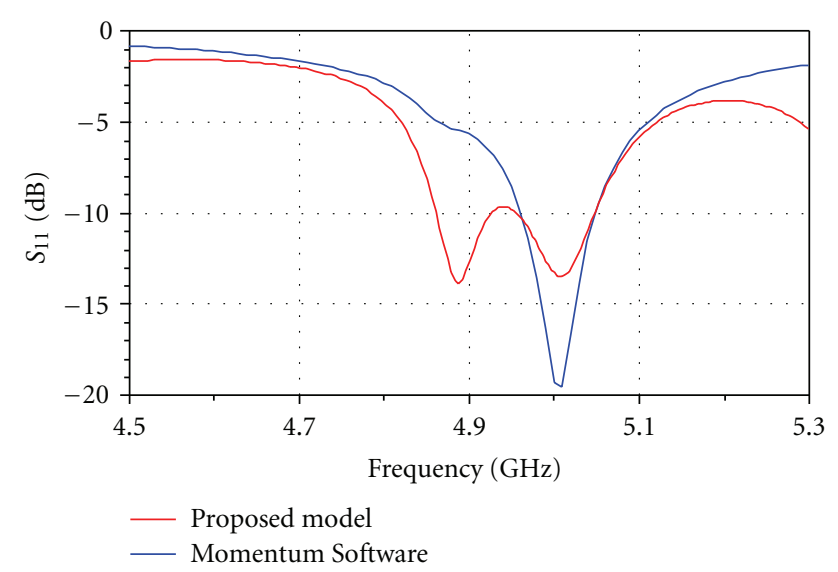

FIgURE 10: Simulated input antenna array return loss.

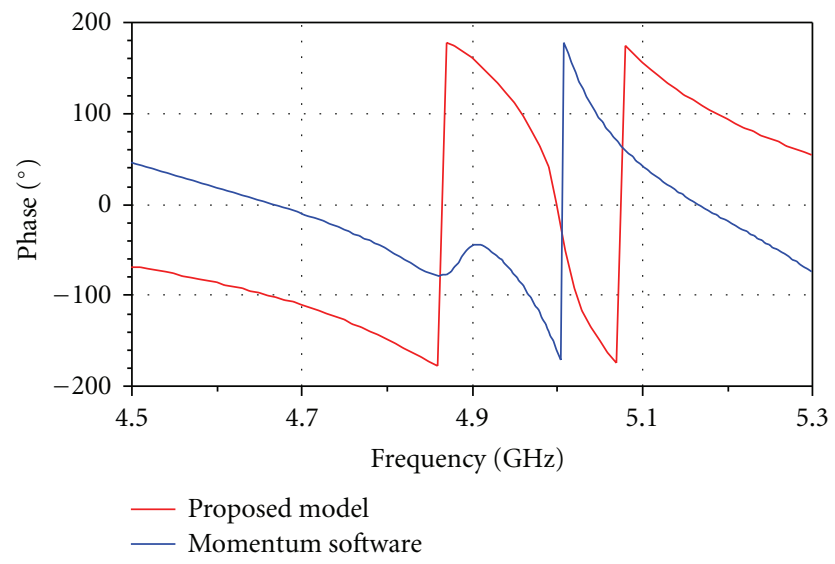

FIgURE 11: The antenna array input-reflected phase.

thickness $h$ of $1.6 \mathrm{~mm}$, and a loss tangent of about 0.019 and $0.05 \mathrm{~mm}$ conductor thickness.

The mask of the multilayer bow-tie antenna array with dimensions is shown in Figure 4.

The simulated input return loss of multilayer bow-tie antenna array is displayed at the frequency $2.4 \mathrm{GHz}$ in Figure 5.

The representation of the reflection coefficient as a function of the resonance frequency is shown by the appearance of several resonance frequencies, which is a characteristic of the multiband antenna array.

The results show the appearance of a resonant mode at the frequency $2.4 \mathrm{GHz}$ and a good agreement by the proposed model and the Momentum software. It appears that a peak of $-17.52 \mathrm{~dB}$ using transmission line model with a light shift by the moment method provides a return loss of $-11.24 \mathrm{~dB}$ at the frequency $2.42 \mathrm{GHz}$.

The moments results and those obtained from transmission line model of the input phase of return loss for this antenna array are shown in Figure 6.

From Figure 6, both models have the same shape and we note very well that the phase is null by the two models at the resonant frequencies, which means a perfect adaptation.

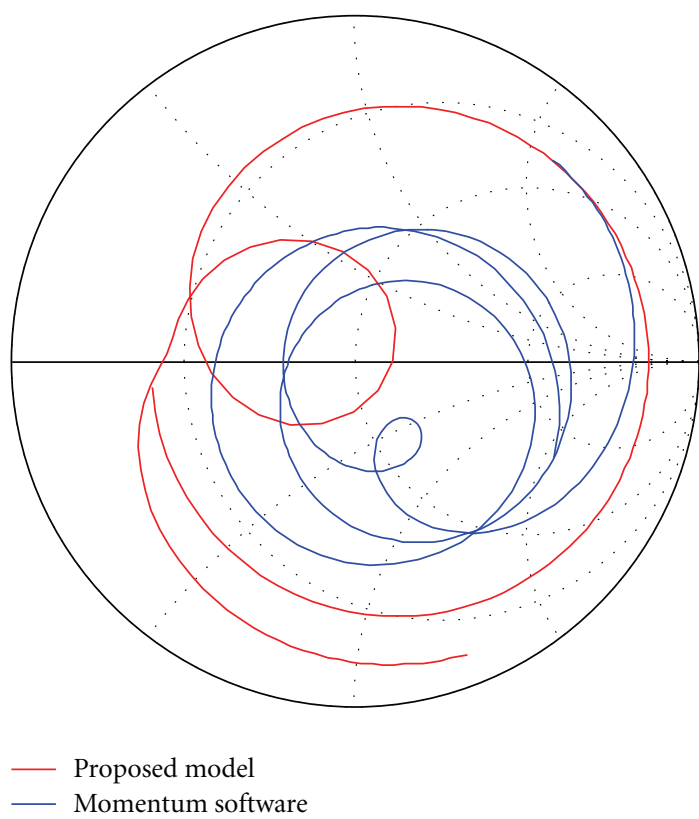

FIgURE 12: Smith's chart of the input impedance locus.

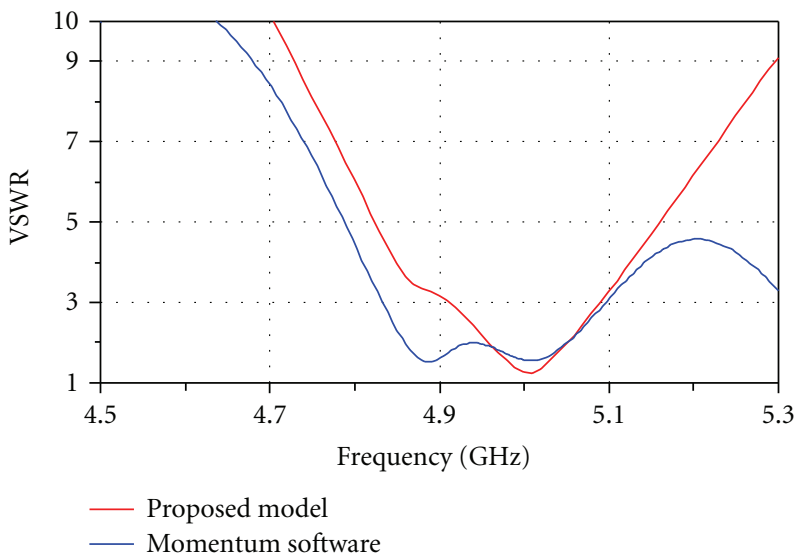

FIgURe 13: Bow-tie antenna array VSWR.

The impedance locus of the antennas array from 1.5 to $3 \mathrm{GHz}$ is illustrated on Smith's chart in Figure 7.

It can be seen from Figure 7 that both models represent the locations of input impedances in a manner almost identical; this justifies the good agreement between the two models.

From Figure 8, there is a good agreement between the two models; the level of VSWR is close to unity, implying a good adaptation of the antenna array and precision of the model line transmission.

4.2. Bow-Tie Antenna Array Operating at the Resonant Frequency $5 \mathrm{GHz}$. The selected configuration is shown in Figure 9 and consists of six bow-tie identical patches multilayer operating at the resonant frequency $5 \mathrm{GHz}$.

The antenna array is to be designed on substrate which has a relative permittivity $\varepsilon_{r}$ of 2.54 , a dielectric thickness $h$ 


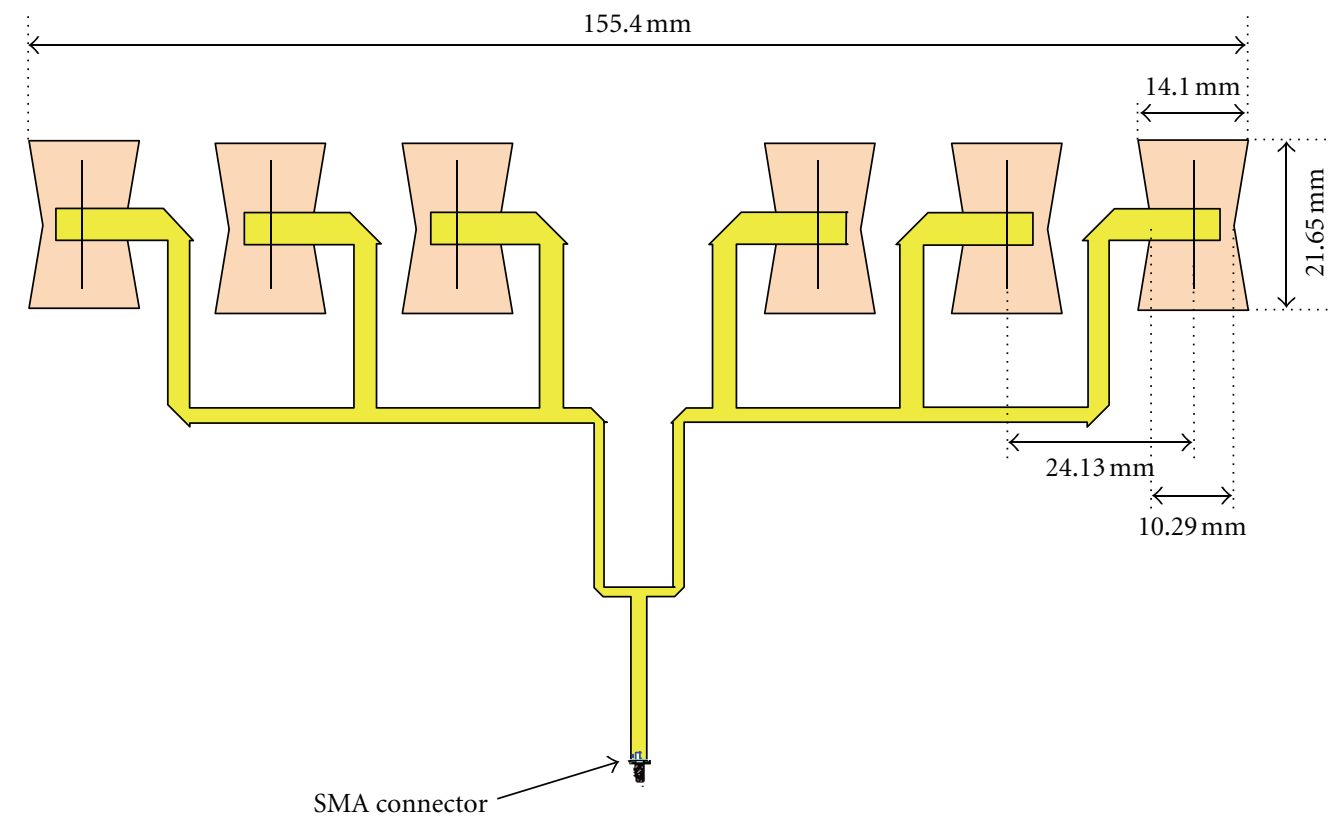

FIGURE 14: Mask of the multilayered bow-tie antenna array operating at the frequency $8 \mathrm{GHz}$.

of $1.6 \mathrm{~mm}$, and a loss tangent of about 0,019 and $0.05 \mathrm{~mm}$ conductor thickness. A rectangular slot with $L_{\text {ap }}=18 \mathrm{~mm}$ and width $W_{\text {ap }}=0.6 \mathrm{~mm}$ is used for coupling the patch to a microstrip line of length $L_{f}=10 \mathrm{~mm}$, etched on substrate which has a relative permittivity $\varepsilon_{r}$ of 2.54 , a dielectric thickness $h$ of $1.6 \mathrm{~mm}$, and a loss tangent of about 0.019 and $0.05 \mathrm{~mm}$ conductor thickness.

The multilayer bow-tie antenna array designed with dimensions in millimeter is represented in Figure 9.

The mask of the multilayer bow-tie antenna array with dimensions is shown in Figure 10.

From Figure 10, the resonance of antenna array is correctly predicted by both models to be $5 \mathrm{GHz}$, and as a result we note a peak of about $-13.54 \mathrm{~dB}$ obtained by transmission line model and of about $-19.6 \mathrm{~dB}$ by the moment's method.

The moments results and those obtained from transmission line model of the input phase of return loss for this antenna array are shown in Figure 11.

The reflected phase is null by the two models in spite of the shift observed by transmission line model.

The input impedance locus of the multilayer bow-tie antenna array is illustrated on Smith's chart in Figure 12.

It is observed that the curves of the two models pass by the axis of $50 \Omega$. The simulated VSWR is represented on Figure 13.

According to Figure 13, there is good agreement between the two models (transmission line model and the moment method). Around the resonant frequency the VSWR is close to unity implying a good adaptation of the network.

\subsection{Bow-Tie Antenna Array Operating at the Resonant Freq-} uency $8 \mathrm{GHz}$. In this section, other geometry is analyzed by using the method proposed in this paper. The antenna array

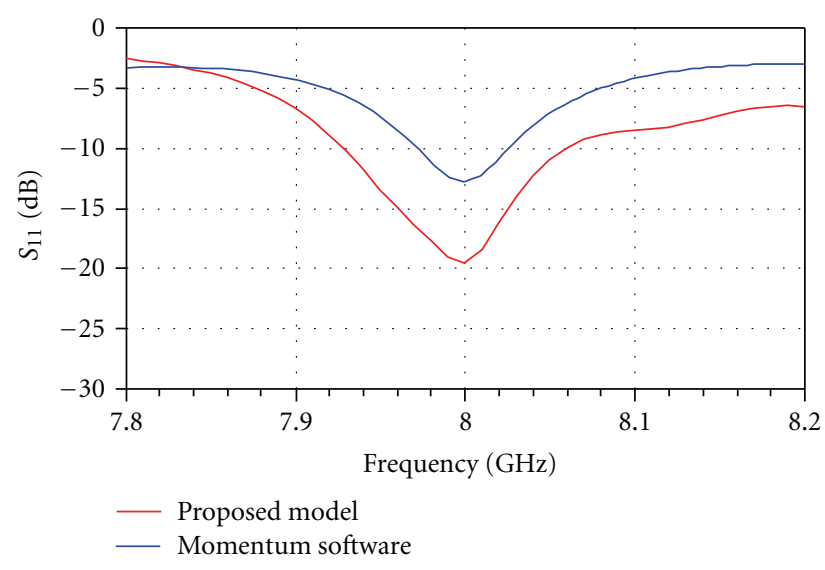

FIGURE 15: Simulated input antenna array return loss.

consists of six bow-tie identical multilayer patches, as shown in Figure 14 and is designed to operate at $8 \mathrm{GHz}$ frequency.

The antenna array is to be designed on substrate which has a relative permittivity $\varepsilon_{r}$ of 2.54 , a dielectric thickness $h$ of $1.6 \mathrm{~mm}$, and a loss tangent of about 0,019 and $0.05 \mathrm{~mm}$ conductor thickness. A rectangular slot with $L_{\mathrm{ap}}=16 \mathrm{~mm}$ and width $W_{\text {ap }}=2.6 \mathrm{~mm}$ is used for coupling the microstrip line of $10 \mathrm{~mm}$ length to the patch, etched on a substrate which has a relative permittivity $\varepsilon_{r}$ of 2.54 , a dielectric thickness $h$ of $1.6 \mathrm{~mm}$, and a loss tangent of about 0,019 and $0.05 \mathrm{~mm}$ conductor thickness.

Figure 14 presents the mask layout for multilayer bow-tie antenna array at the resonant frequency $8 \mathrm{GHz}$.

The simulated input return loss of multilayer bowtie antenna array is displayed at the frequency $8 \mathrm{GHz}$ in Figure 15. 


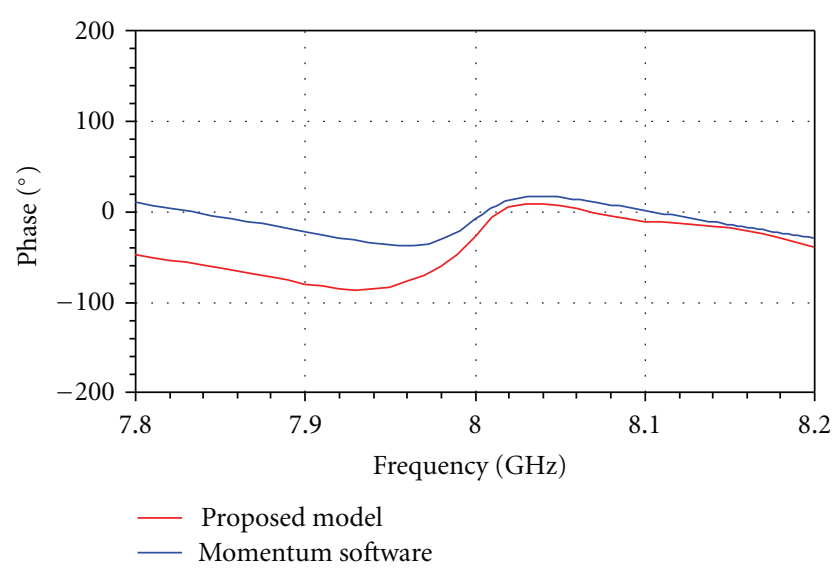

FIgURE 16: The antenna array input-reflected phase.

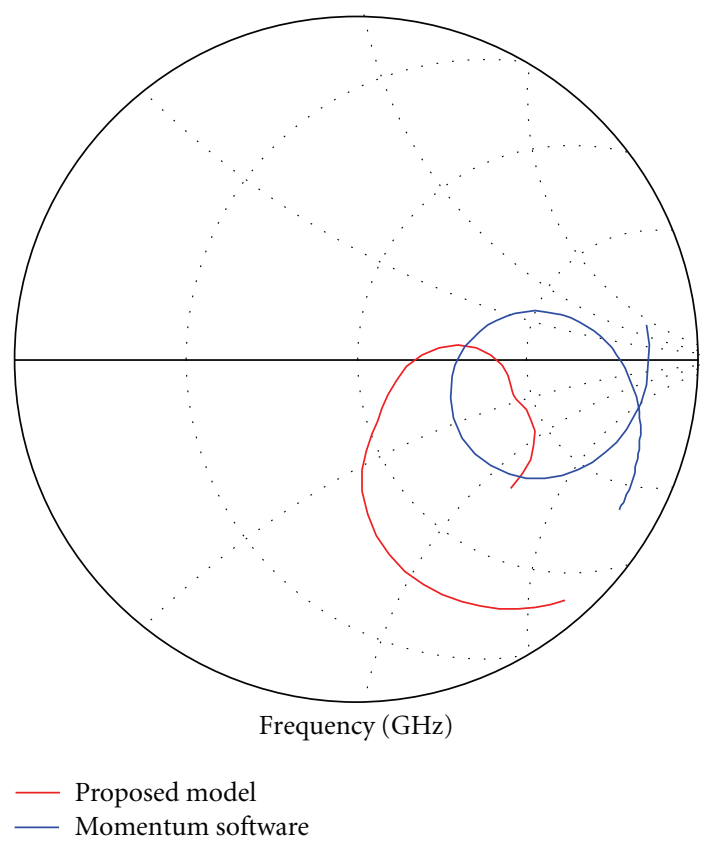

FIGURE 17: Smith's chart of the input impedance return losses.

From Figure 15, it is observed that the resonance of the antenna array is correctly predicted to $8 \mathrm{GHz}$ by the two models. It shows a peak of $-19.60 \mathrm{~dB}$ using transmission line model and a peak of $12.84 \mathrm{~dB}$ by the moment method.

The moments results and those obtained from transmission line model of the input phase of return loss for this antenna array are shown in Figure 16.

As shown in Figure 16, a good agreement between the transmission line model and moment's method, the simulation results also show that the phase is null by the two models.

The impedance locus of the multilayer bow-tie antenna array is illustrated on Smith's chart in Figure 17.

The input impedance or the antenna has been calculated over a frequency range of $7.8-8.2 \mathrm{GHz}$. It can be seen from

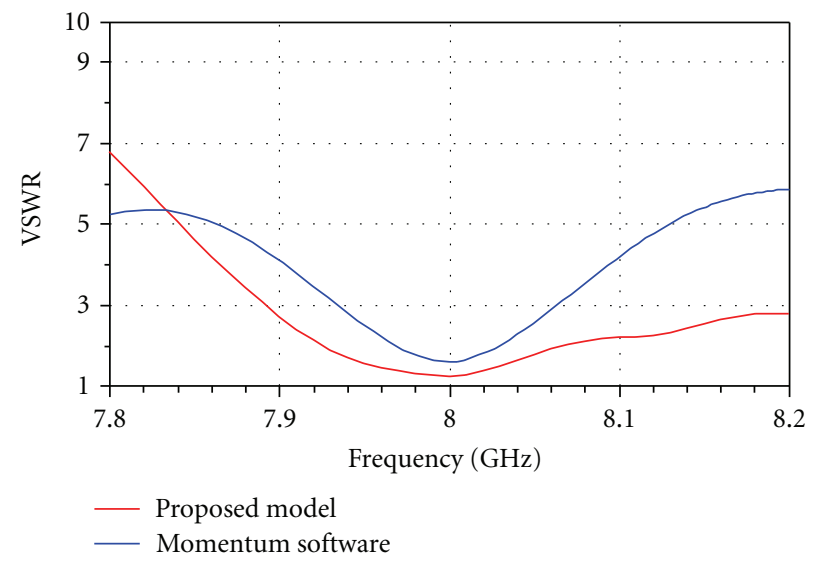

Figure 18: Bow-tie antenna array VSWR.

TABLE 1: Comparison between transmission line model and method of moments.

\begin{tabular}{lcccc}
\hline $\begin{array}{l}\text { Antennas } \\
\text { arrays }\end{array}$ & Model & $\begin{array}{c}\text { Return } \\
\text { loss } \\
(\mathrm{dB})\end{array}$ & $\begin{array}{c}\text { Resonant } \\
\text { frequency } \\
(\mathrm{GHz})\end{array}$ & $\begin{array}{c}\text { Frequency } \\
\text { shift } \\
(\%)\end{array}$ \\
\hline $2.4 \mathrm{GHz}$ (RFID) & MLT & -17.52 & 2.4 & $0.8 \%$ \\
& MoM & -11.24 & 2.42 & \\
$5 \mathrm{GHz}$ (WIFI) & MLT & -13.54 & 5 & $0.2 \%$ \\
& MoM & -19.60 & 5.01 & \\
$8 \mathrm{GHz}$ (RADAR) & MLT & -19.60 & 8 & $0 \%$ \\
& MoM & -12.84 & 8 & \\
\hline
\end{tabular}

Figure 17 that the curves of the two models pass by the axis of $50 \Omega$.

From Figure 18, in the vicinity of the resonant frequency the VSWR is close to the unit which corresponds to an ideal matching.

To better illustrate the results obtained in terms of adaptation, the comparison of the results in terms of return loss and resonant frequency between the transmission line model (MLT) and the method of moments (MoM) is summarized in Table 1.

Table 1 shows that the largest amount of frequency shift is produced by antenna $2.4 \mathrm{GHz}$ which produced a resonance frequency of $2.4 \mathrm{GHz}$ by MLT and $2.42 \mathrm{GHz}$ by MoM, a shift of about $0.8 \%$ from $2.4 \mathrm{GHz}$. The lowest frequency shift is shown by antenna $8 \mathrm{GHz}$, a shift of about $0 \%$ from $8 \mathrm{GHz}$.

The return losses generated by all antennas arrays, which are all in the magnitudes less than $-11 \mathrm{~dB}$, show that a good impedance matching has been achieved in both models.

\section{Conclusion}

In this paper three multilayered bow-tie antennas arrays have been designed, which consist of 6 identical bowtie patch elements in parallel or corporate feed to resonate at the frequencies $2.4 \mathrm{GHz}, 5 \mathrm{GHz}$, and $8 \mathrm{GHz}$ corresponding to RFID, WIFI, and radars applications using an equivalent circuit. The transmission line model can be successfully 
used to design the corporate-fed multilayer bow-tie antennas arrays, and even though the model is conceptually simple, it still produces accurate results in a relatively short period of computing time. The proposed transmission line model showed its interest in the design of different multilayered bow-tie antennas arrays feed in parallel, predicting the correct resonance frequency for different applications in telecommunications. The results obtained highlighted a good agreement between the transmission line model and the moment's method. A comparison of the results produced by the final model with the moment's method showed the validity of the proposed model.

\section{References}

[1] M. Abri, N. Boukli-hacene, and F. T. Bendimerad, "Application du recuit simulé à la synthèse d'antennes en réseau constituées d'éléments annulaires imprimés," Annales Des Télécommunications, vol. 60, no. 11-12, pp. 1424-1440, 2005.

[2] G. Dubost, "Broadband circularly polarized flat antenna," in Proceedings of the International Symposium on Antennas and Propagat, pp. 89-92, Sendai, Japan, 1978.

[3] M. M. Alam, "Design and performance analysis of microstrip array antenna," in Progress in Electromagnetic Research Symposium Proceedings, Moscow, Russia, August 2009.

[4] M. Abri, N. Boukli-Hacene, and F. T. Bendimerad, "Weighted array design of an aperture coupled printed antennas," in Proceedings of the Mosharaka Multi-Conference on Communications, Signals and Control (MM-CSC '07), Amman, Jordan, 2007.

[5] M. F. Bendahmane, M. Abri, F. T. Bendimerad, and N. BoukliHacene, "A simple modified transmission line model for inset fed antenna design," International Journal of Computer Science Issues, vol. 7, no. 5, pp. 331-335, 2010.

[6] M. Himdi, J. P. Daniel, and C. Terret, "Transmission line analysis of aperture-coupled microstrip antenna," Electronics Letters, vol. 25, no. 18, pp. 1229-1230, 1989.

[7] C. A. Balanis, Antenna Engineering, Willey, 2nd edition, 1982. 

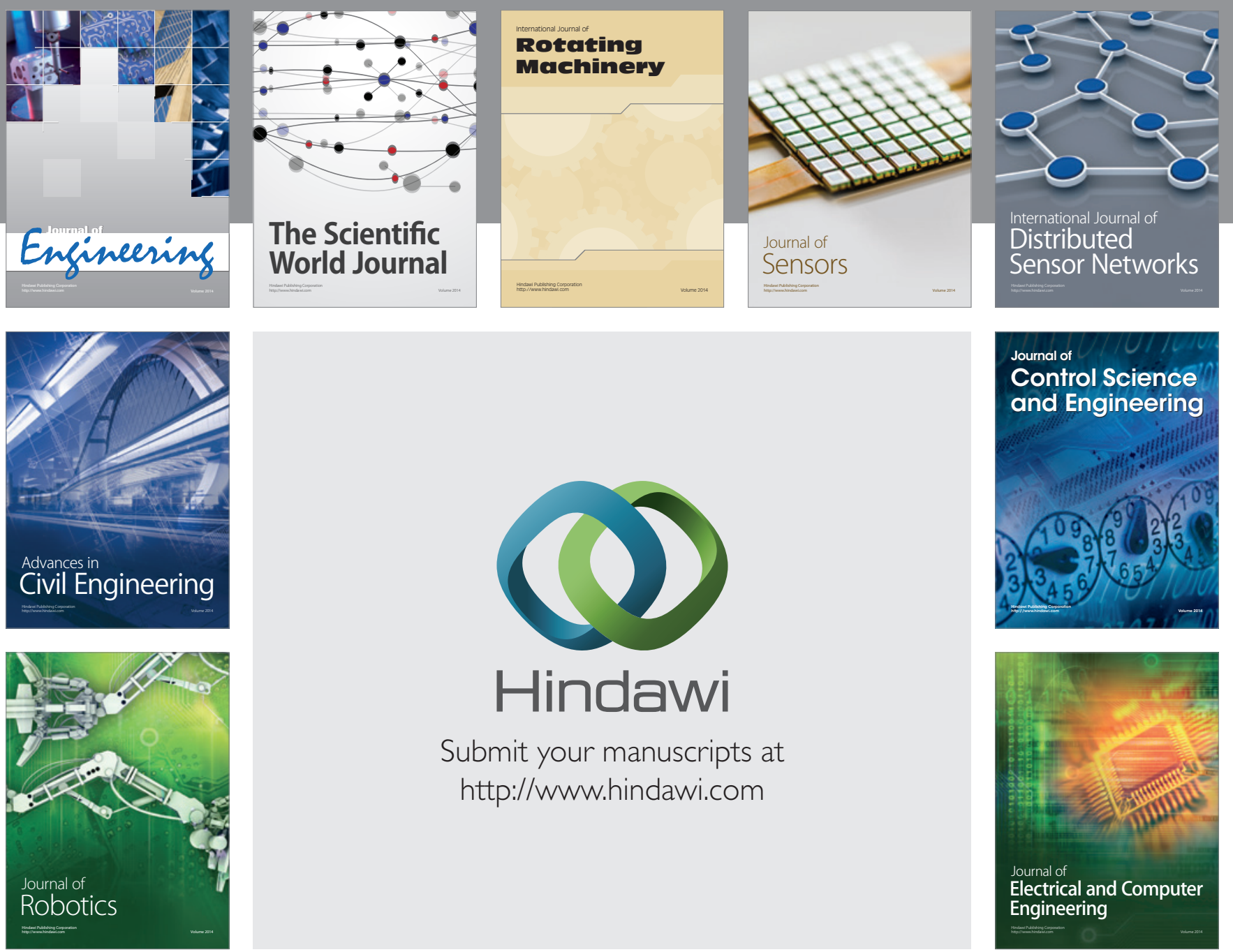

Submit your manuscripts at

http://www.hindawi.com
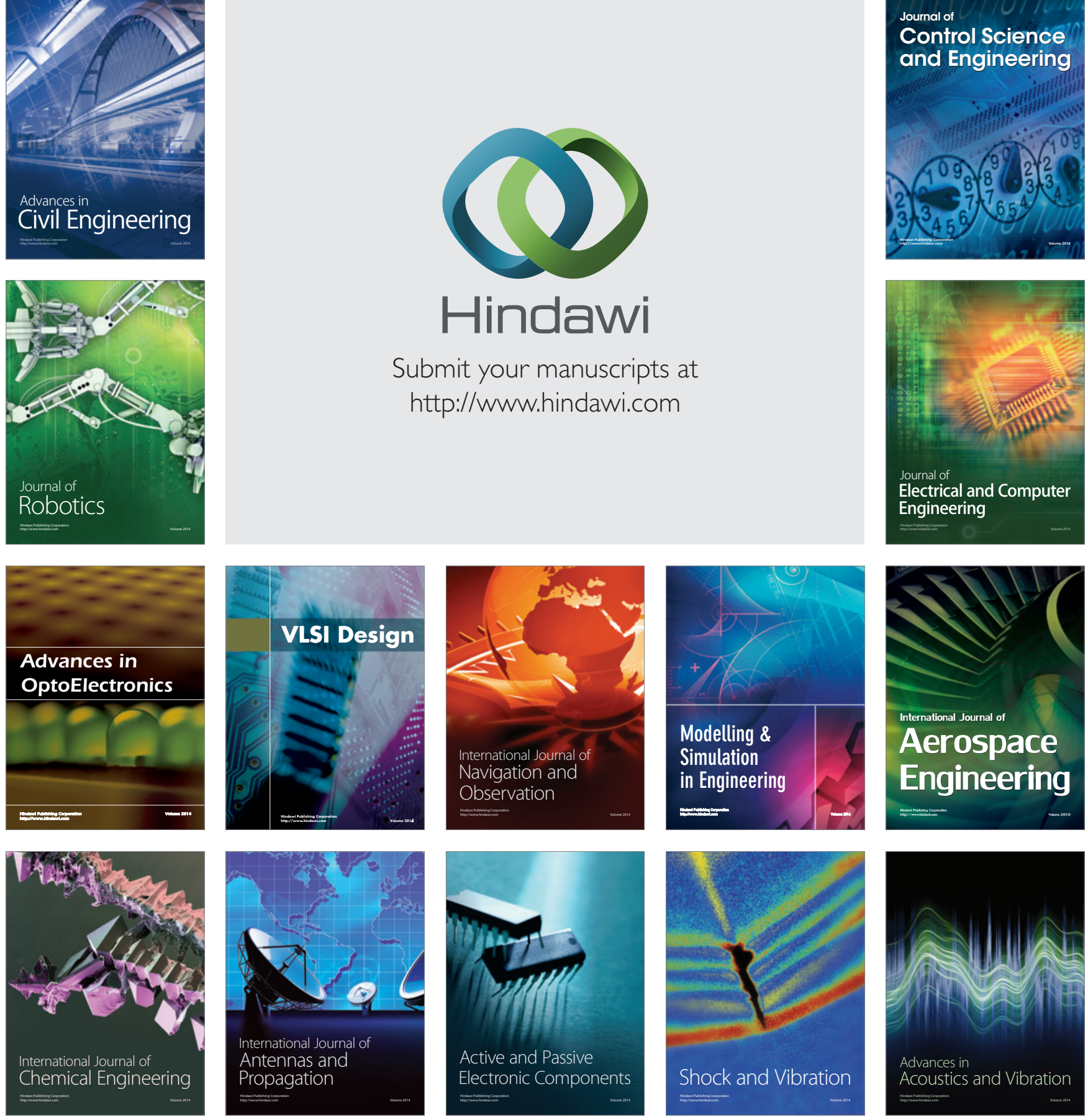